\title{
CONTRIBUIÇÕES DE MICHEL FOUCAULT PARA ANALISAR DOCUMENTOS E ARQUIVOS NA JUDICIALIZAÇÃO/JURISDICIONALIZAÇÃO'
}

\author{
Flávia Cristina Silveira Lemos ${ }^{2}$ \\ Universidade Federal do Pará, Belém-PA, Brasil \\ Dolores Cristina Gomes Galindo \\ Universidade Federal do Mato Grosso, Cuiabá-MT, Brasil \\ Jorge Moraes da Costa \\ Universidade Federal do Pará, Belém-PA, Brasil
}

\begin{abstract}
RESUMO. Nesse artigo pretendemos ressaltar a produção histórica encontrada em arquivos e documentos, bem como as práticas de generalização de uma sociedade punitiva no âmbito das relações entre normas e leis, e também do poder, direito e verdade, de acordo com estudos de Michel Foucault a respeito da soberania jurídica, da disciplina, da biopolítica e da segurança como dispositivo político de governo das condutas. Na atualidade o uso dos documentos e de arquivos para criminalizar, encarcerar e segregar os desviantes sociais é uma prática cotidiana, e funciona pelo dispositivo de confissão nas adjacências do Poder Judiciário, operando as noções de risco e perigo, em termos de biopolítica. Já a escrita disciplinar aciona a constituição de casos e dossiês, por meio dos exames, das observações vigilantes e da sanção normalizadora, em uma microeconomia penal. É relevante criticar essas práticas e pensar campos de possibilidade de resistência a essas escritas de uma memória das infâmias na judicialização da vida.
\end{abstract}

Palavras-chave: Processos legais; história, Foucault, M.

\section{CONTRIBUTIONS OF MICHEL FOUCAULT TO ANALYZE DOCUMENTS AND FILES ON JUDICIALIZATION/JURISDICTIONALIZATION}

\begin{abstract}
In this article we aims to highlight the historical production among files, documents and practices generalization of a punitive society, in relations between norms and laws, and also the power, right and truth , according to studies of Michel Foucault regarding legal sovereignty, discipline, biopolitics and security as a political government system of conducts. The use of the documents and files to criminalize, incarcerate and segregate social deviants is an everyday practice today and runs through the device of confession in the vicinity of the judiciary, operating the notions of risk and danger in terms of biopolitics. The disciplinary writing triggers the formation of cases and dossiers, by means of tests, vigilant observations and regulatory sanction, in a criminal microeconomics. It is important to criticize these practices and thinking about field of possibilities of résistance to those written in a memory of the infamies in the judicialization of life.
\end{abstract}

Keywords: Legal processes; history; Foucault, M.

\section{CONTRIBUCIONES DE MICHEL FOUCAULT PARA ANALIZAR DOCUMENTOS $Y$ ARCHIVOS DE LA LEGALIZACIÓN/JURISDICCIONALIZACIÓN}

RESUMEN. En este artículo se propone destacar la producción histórica entre archivos, documentos y prácticas de la generalización de una sociedad punitiva, en las relaciones entre las normas y las leyes, así como el poder, la justicia y la verdad, de acuerdo a los estudios de Michel Foucault sobre de la soberanía jurídica, la disciplina, la biopolítica y el dispositivo de seguridad como los conductos de las políticas gubernamentales. El uso de los documentos y archivos de criminalizar, encarcelar y segregar desviados sociales es una práctica cotidiana, en la actualidad y se ejecuta a través del dispositivo de la confesión en las proximidades de la judicatura, que opera las nociones de riesgo y peligro en términos de biopolítica. Ya, escribir casos y expedientes disciplinarios, por medio

\footnotetext{
1 Apoio e financiamento: Conselho Nacional de Desenvolvimento Científico e Tecnológico (CNPq).

2 Endereço para correspondência: SHCES, Quadra 1105, bloco H, apto 302, Cruzeiro Novo - CEP 70.658-150 Brasília-DF, Brasil. E-mail: flaviacslemos@gmail.com.
} 
de pruebas, observaciones vigilantes y normalizar la sanción, dentro de la microeconomía criminal. Es importante criticar estas prácticas y pensar campo de posibilidades de resistencia a los escritos en una memoria de las infamias de la judicialización de la vida.

Palabras-clave: Procesos legales; historia; Foucault, M.

A emergência da nova história possibilitou uma ruptura com a história baseada em provas e investigada com a busca das chamadas fontes oficiais, depositadas em arquivos públicos com objetivos nacionalistas. Dessa forma, a preocupação central dos que trabalhavam com essas fontes era narrar os feitos de estadistas, de monarcas e de militares. Os temas das escritas positivistas e tradicionais eram datas, decisões políticas e acordos econômicos (Farge, 2011). Já a nova história cultural permite analisar historicamente novos questionários, objetos, temas e problemas, que passam a ser abordados pelo historiador com a abertura de outros olhares e do estudo de arquivos que antes os historiadores não consideravam importantes para a escrita da história (Farge, 2011).

O trabalho de ampliação dos objetos, das perguntas e das fontes historiográficas propiciou fazer perguntas e escrever a história de outras maneiras. Abriu um fértil campo de estudos de resistência e de contrapoderes em relação ao movimento tradicional, que se restringia a contar a historia de militares e de estadistas. A problematização da escrita e análise como relação de poder e de saber que gera efeitos cotidianos nos corpos, nas subjetividades e nas relações sociais permitiu trabalhar com os documentos de arquivos públicos e privados de diversos equipamentos e grupos sociais, colaborando com diferentes áreas.

A análise histórica dos arquivos do Poder Judiciário, das instituições de assistência social, dos hospitais, das escolas e de uma série de outros estabelecimentos, atravessados pela finalidade estratégica da prova, possibilita pensar as práticas sociais em seus efeitos políticos, culturais, subjetivos e econômicos. A noção de prova está ligada a uma determinada maneira de tratar os vestígios como fatos e registros fidedignos dos acontecimentos ocorridos, supostamente neutros e sem qualquer viés situado no tempo e lugar em que fora produzido.

Castro (2008) destaca que a corrente da nova história altera esse enfoque e começa a abordar os documentos e os arquivos em que estariam armazenados como artefatos e não como provas. Indagar os valores arrolados para a criação de arquivos, os interesses arregimentados na elaboração dos documentos e na definição dos lugares de recebê-los e guardá-los traz uma diversidade de implicações a ser alvo de inquietações e perguntas (Albuquerque Jr., 2009). Outro aspecto diz respeito à interrogação do financiamento dessas práticas para pensar sobre a maneira de organizar os registros, sobretudo, pelo que se poderá fazer por meio dos documentos fabricados nos atendimentos às pessoas.

Procura-se analisar historicamente os efeitos da complexa trama de circulação dos relatórios, fotografias, publicações, cartas, gavetas, formulários e dossiês, armários e espaços em que são guardados os documentos e, por fim, as decisões que são tomadas com toda essa massa de acúmulo de narrativas sobre os corpos e seus atos de desvio, celebração e punição. Em meio a essas tramas e redes de intrigas, interessa-nos neste artigo fazer uma breve problematização do uso dos documentos e de seus suportes em arquivos, como os do Poder Judiciário e de instituições normalizadoras afins. Documentos e arquivos resultantes de práticas disciplinares e biopolíticas, que na modernidade operam na relação entre poder, direito e verdade, produzem efeitos nas decisões judiciais que nos deixam sobremaneira perplexos com o que fazemos de nós mesmos e com os outros. Numa trama histórica recheada de práticas de registros e encaminhamentos, detalhes do cotidiano e infâmias minúsculas que ganham visibilidade e importância são capturados em gravações de áudio e vídeo, em papéis e álbuns, tornam-se provas em exames e disputas e são armazenados em gavetas, pastas e prontuários e usados para realizar encaminhamentos aos cárceres e lugares de reclusão e internamento, por exemplo.

A captura documental passou a sustentar uma série de maneiras de governar as condutas e puni-las, em nome da vida e da proteção, extraindo/produzindo a confissão nos minuciosos relatórios das perícias de saber-poder que constituíram $\mathrm{o}$ dispositivo judicializante $\mathrm{e}$ 
jurisdicionalizante da vida - confissão cuja força embasa um amplo espectro de ciências e técnicas cujos procedimentos variam da oitiva à escuta. Prado Filho (2012), numa análise das relações de proveniência do inquérito e da confissão, observa as intrincadas articulações destas tecnologias para a produção de verdade nas práticas jurídicas contemporâneas:

\begin{abstract}
... tal como acontece com o inquérito, a confissão irá transbordar os limites da sua aplicação religiosa para difundir-se em uma multiplicidade de relações e práticas sociais, institucionais e por campos de conhecimento diversos. Também a exemplo do que se passa com o inquérito, ela migra diretamente do confessionário cristão para a Inquisição e daí para as práticas jurídicas, adquirindo aquele poder já citado, de interromper um processo judicial a qualquer momento, desde que haja confissão de culpa pelo réu. (Prado Filho, 2012, p. 108).
\end{abstract}

Com a intensificação dos processos judiciais, os documentos ganharam estatuto de verdade e fazem operar o aumento da punição, inclusive pela multiplicação das aberturas processuais à confissão: sempre haverá tempo para confessar a culpa, o delito, o desvio. Os registros escritos passaram a ser utilizados como armas em litígios infindáveis, resultando em uma gigantesca inflação jurídica. Em seus estudos Michel Foucault cada vez mais se interessou em analisar os documentos de arquivos de instituições em que determinados grupos e suas práticas eram desqualificados e os efeitos dessas práticas no campo judicial e nas intervenções a ele adjacentes, no deslizamento entre leis e normas.

Foucault (1979) afirmou sua paixão pelos arquivos e documentos referentes aos poderes e saberes dirigidos aos corpos de pessoas que foram consideradas infames e cujas vidas foram transformadas em dossiês que, ao serem formulados, marcaram-nas pelo resto de sua existência. Lutas foram (e continuam a ser) travadas sobre o quê e como registrar, onde e de que forma guardar, como organizar o arquivo e de que maneira torná-lo politicamente e eticamente útil à vida pela história denominada efetiva por Michel Foucault a partir das contribuições de Friedrich Nietzsche.

Dessa maneira, a nova história criou uma modalidade de narrativa e analítica capaz de engendrar visibilidades de outras histórias e memórias com o objetivo de fazer a insurreição dos saberes sujeitados e efetuar a produção de lugares outros de existências, heterotopias e contrapoderes diante da captura dos desvios nas malhas do dispositivo da confissão, no âmbito da administração social e penal.

Os arquivos da infâmia forjam lugares de menor valia para aqueles que são alvo das políticas de administração dos corpos e das práticas dos aparatos panópticos de vigilância do cotidiano. Todos aqueles classificados como desviantes se tornam anormais por meio de um sistema de anotação confessional e médicojurídica. Esse regime de escrita das pequenas infâmias acumula e inventa inimigos da sociedade - como doentes, loucos, perigosos, criminosos, negligentes, violentos, drogados e portadores de outras insígnias que sustentavam práticas de segregação supostamente em defesa da sociedade. Foucault (1999a, p. 159) afirma:

\begin{abstract}
A criança, o doente, o louco, o condenado se tornaram, cada vez mais facilmente a partir do século XVIII e segundo uma via que é a da disciplina, objeto de descrições individuais e de relatos biográficos. Esta transcrição por escrito das existências reais funciona como processo de objetivação e de sujeição. (Foucault, 1999a, p. 159).
\end{abstract}

Diante desse cenário, torna-se necessária uma crítica à política da fabricação de casosdocumentos engendrados pelos mecanismos disciplinares e por suas relações com as práticas de governo da vida em nome da suposta defesa da sociedade. Problematizam-se os procedimentos por meio dos quais a administração social se apropria das histórias de vida para julgar, criminalizar e encarcerar. A obra de Foucault é marcada pela preocupação em utilizar a análise histórica dos documentos para resistir ao controle social e forjar ferramentas de inquietação no presente em termos do que estamos fazendo com os outros e com nós mesmos.

O uso de documentos para intensificar as práticas do Poder Judiciário em prol do enfraquecimento político do Executivo e do Legislativo implicou na ênfase da soberania jurídica no Estado Democrático do Direito, especialmente com encomendas de leis. A difusão de uma preocupação com a ordem social 
se tornou um procedimento presente na jurisdicionalização em dossiês, em processos, em laudos e perícias, na maioria dos países, a partir da emergência do Estado Moderno.

Numa análise que coloca em xeque a crescente jurisdicionalização e judicialização da vida, simultaneamente generalizadas em sua extensão e minuciosas em seus procedimentos, os arquivos podem ser pensados como dispositivos vivos, pois ganham o estatuto de produção de uma história útil à vida como atitude crítica do presente.

\section{A TRANSFORMAÇÃO DA INFÂMIA EM PERIGO NOS DOCUMENTOS GUARDADOS EM ARQUIVOS DISCIPLINARES}

Anotar infâmias em relatórios e organizá-las em quadros de semelhança para punir e julgar é algo recente em nossa história, datando de apenas alguns séculos. Fabricar arquivos com documentos que narram detalhes e pequenas divergências e acumulam minúcias de desvios sociais que não cairiam nas malhas da justiça se não fosse um conjunto de práticas de uma sociedade cada vez mais punitiva e de intensa vigilância, constituiu-se como uma prática de castigo, de correção obstinada e de vingança.

Relatos minúsculos são formulados como resultado de intrigas entre vizinhos, familiares, trabalhadores e amigos, disputas de vaidades entre membros da burocracia administrativa do Estado e da elite religiosa, de furtos, de desobediências escolares, de brigas por herança e fugas de lugares de internação, de não adesão a tratamentos, por deserções do exército, por desentendimentos entre casais e por conflitos religiosos e políticos. Para cada intriga e dissidência, inquéritos e exames são realizados tendo em vista a produção de saberes sobre os corpos e modos de vidas classificados como infames por trabalhadores sociais, educadores e operadores do direito.

\footnotetext{
Enquanto os sistemas jurídicos qualificam os sujeitos de direito, segundo normas universais, as disciplinas caracterizam, classificam, especializam; distribuem ao longo de uma escala, repartem em torno de uma norma, hierarquizam os indivíduos em relação uns aos outros, e, levando ao limite, desqualificam e invalidam (Foucault, 1999a, p. 183).
}

Fazer falar em confissões e extrair o efeito da aquisição de uma prova e da produção da verdade sobre os acontecimentos em inquirições cotidianas e permanentes se tornou um ato banalizado e uma disciplina como regra repetida em rituais políticos da verdade em nome da punição modulada nas mais variadas penalidades. No bojo da intensificação da difusão de um projeto baseado na ordem social, as decisões cotidianas se fundamentam em modelos que articulam normas sociais. Os saberes especializados vão sendo requisitados contundentemente e as tensões são mediadas e resolvidas cada vez mais na instância dos tribunais. Perícias de expertises passam a definir vidas e lançam mão das histórias de vida interpretadas pelo crivo dos modelos científicos, avaliando os corpos em verdade e gerando efeitos de poder sobre eles.

As dissidências mais simples são transformadas em casos a serem alvo de medicalização e criminalização simultaneamente. Os processos jurídicos se tornam cada vez mais comuns e frequentes. Neles, normas e leis são misturadas, biografias e delitos materializam e sustentam práticas de prisão, punições diversas, correções, castigos e internações (Foucault, 2008a). As histórias de vida se tornam parte de uma tática utilizada para internar e invalidar os desviantes de nossa sociedade, desautorizando suas falas e suas existências e sustentando uma intervenção disciplinar generalizada para garantir a lei e a ordem e diminuir revoltas e resistências (Foucault, 1996) na esfera da jurisdicionalização e judicialização da vida.

Precisemos conceitualmente o sentido que os processos de jurisdicionalização e judicialização da vida adquirem na obra foucaultiana.

A soberania jurídica, para Foucault (1988, 2008b), baseia-se na noção de lei como governo dos corpos em termos de uma visão de poder baseada no Estado Democrático de Direito. Por meio dela se dita o que é lícito e ilícito, permitido e proibido. Aqui se tem a judicialização da vida com a prerrogativa de uma formalidade no campo do sujeito de direitos, penalizado pelo descumprimento de seus deveres em uma sociedade enquadrada pelo pacto de um contrato, em termos de defesa social contra inimigos inventados e reinventados na classificação dos que se insurgem e resistem aos mecanismos de controle social. 
Não obstante, essa não é a única maneira de pensar e analisar as relações de poder, conforme o autor (Foucault, 1988, 2008b). Para ele, poder como lei e ação do Estado são formas terminais do poder, e não formas iniciais. $O$ poder disciplinar seria mais ramificado e generalizado no campo das relações dinâmicas cotidianas e estaria baseado em uma racionalidade punitiva, também na sociedade contemporânea, pela norma e pelo desvio dessa norma, avaliada e julgada em outras esferas e com a aplicação de outras punições. Nesse caso, estamos falando do castigo disciplinar por meio da sanção normalizadora e da judicionalização dos desvios das normas.

Dessa maneira, a judicionalização implica uma primazia da norma sobre a lei nos processos de subjetivação atuais, baseados nas práticas punitivas, mas sem perder de vista a articulação com a lei e com a produção de saberes. Por isto o triângulo poder, direito e verdade, do qual Foucault (1979) trata de forma brilhante, ao destacar a relação entre poder, verdade e Direito, nas relações lei e norma, materializadas no cotidiano das práticas punitivas na sociedade que visa docilizar e submeter politicamente os corpos por estes mecanismos disciplinares e de judicialização.

Ao estudar os processos de normalização e disciplina da sociedade contemporânea, Foucault (1999), em "Vigiar e Punir", assinala que é preciso descrever o poder mais como uma tática do que como lei. Nesse sentido, ele afirma que o direito teria sido colonizado pela norma. Assim, no caso da relação das normas com os regimes de verdade, há uma vinculação com a normalização do Direito, chamada de jurisdicionalização, a qual opera a generalização das práticas punitivas para toda a sociedade. $\mathrm{Ou}$ seja, a judicialização é a sobreposição da lei à norma na máxima valorização das encomendas ao Poder Judiciário de questões as mais simples e corriqueiras de nossas existências. Já, a jurisdicionalização é a sobreposição da norma à lei, na intensificação de punições por toda a sociedade como táticas de sanções normalizadoras; todos os equipamentos sociais e grupos passam a funcionar como pequenos tribunais das normas.

Um poder da escrita é constituído como uma peça essencial nas engrenagens da disciplina. Em muitos pontos, modela-se pelos métodos tradicionais da documentação administrativa. ... As outras relações da escrita disciplinar se referem à correlação desses elementos, à acumulação dos documentos, a seriação, à organização de campos comparativos que permitem classificar, formar categorias, estabelecer médias, fixar normas. (Foucault, 1999a, p. 157158).

Dessa maneira, em "Vigiar e Punir", Foucault (1999a) relata que uma das práticas da sociedade disciplinar emergidas na segunda metade do século XVIII é a produção de um caso por meio de um sistema de anotações e registros, configurando um dossiê como efeito do poder-saber sobre os corpos. Laudos, recibos, formulários, fichas, fotos, carimbos, selos, assinaturas, pesquisas, projetos e relatórios de perícias, programas, pactos e declarações, boletins de ocorrência e processos operam com uma imensa massa documental no deslizamento entre as normas e as leis:

A denúncia, a queixa, a inquirição, o relatório, a espionagem, o interrogatório. $E$ tudo o que assim se diz, se registra por escrito, se acumula, constitui dossiês e arquivos. A voz única, instantânea e sem rastro da confissão penitencial que apagavam o mal apagando-se ela própria é, doravante, substituída por vozes múltiplas que se depositam em uma enorme massa documental e constituem assim, através dos tempos, como a memória incessantemente crescente de todos os males do mundo. O mal minúsculo da miséria e da falta não é mais remetido ao céu pela confidência apenas audível da confissão; ele se acumula sobre a terra sob a forma de rastros escritos. É um tipo de relações completamente diferentes que se estabelece entre o poder, o discurso e o cotidiano, uma maneira totalmente diferente de o reger e de o formular (Foucault, 2006a, p. 213).

Ao falar do exame dos corpos, Foucault (1999a) assinala que essa tecnologia de podersaber disciplinar é uma maneira de avaliar em verdade e forjar relatórios que sustentam decisões sobre as vidas em diferentes esferas, inclusive do Poder Judiciário e das instituições que lhe são adjacentes.

Assim, outro mecanismo disciplinar que está articulado ao regime de escrita e acúmulo de documentos em arquivos é a observação 
hierárquica, por meio da qual se constitui uma massa de relatórios e encaminhamentos, protocolos e saberes. Observa-se, com critérios previstos em documentos de recomendações de programas locais, regionais, nacionais e internacionais, que uma prática vizinha à observação hierárquica é o exame, em que a observação se torna mais meticulosa e individual para premiar e punir comportamentos considerados adequados e não adequados:

O exame faz também a individualidade entrar num campo documentário: seu resultado é um arquivo inteiro com detalhes e minúcias que se constitui ao nível dos corpos e dos dias. O exame que coloca os indivíduos num campo de vigilância situa-os igualmente numa rede de anotações escritas; compromete-os em toda uma quantidade de documentos que os captam e os fixam. Os procedimentos de exame são acompanhados imediatamente de um sistema de registro intenso e de acumulação documentária (Foucault, 1999a, p. 157).

Toda uma microeconomia penal é difundida como valor e exercida por um conjunto de práticas escolares na saúde, no trabalho, na família, na assistência social e nos programas de acesso à cultura, ao esporte e ao lazer. A sanção normalizadora traz esse procedimento de modo mais específico no poder disciplinar. Explica Foucault:

\begin{abstract}
Mas a disciplina traz consigo uma maneira específica de punir, e que é apenas um modelo reduzido do tribunal. O que pertence à penalidade disciplinar é a observância, tudo o que está inadequado à regra, tudo o que se afasta dela, os desvios. É passível de pena o campo indefinido do não-conforme.... O castigo disciplinar tem a função de reduzir os desvios. ... Castigar é exercitar. (Foucault, 1999a, p. 149-150).
\end{abstract}

Assim, a sanção disciplinar se relaciona com o exame e a produção de documentos e com a observação de vigilância para disciplinar os corpos na judicionalização da vida, em que a minúcia da punição esquadrinha os corpos em verdade e os observa, vigia e pune pelo desvio das normas, em uma generalização da sociedade punitiva que opera pela norma antes da lei ou da norma no interior da lei, no caso dos julgamentos de virtualidades, como é o caso do acirramento do castigo na pena de prisão para os que são avaliados como perigosos, e até mesmo seu aprisionamento perpétuo em função do exame e da sanção disciplinar pela história de desvios das normas registrada em arquivos biográficos da construção do indivíduo criminoso.

Nessa perspectiva, Foucault (1988, 1999b, 2001, 2008a, 2008b) avança no debate e sua análise para um campo macropolítico da gestão da vida, em que amplia o estudo das práticas punitivas por meio dos conceitos de biopolítica e de segurança, que estariam sustentados no racismo de sociedade e de Estado, segundo o autor.

\section{BIOPOLÍTICA E SEGURANÇA NOS DOCUMENTOS E ARQUIVOS RACISTAS}

Nos últimos dois séculos e meio produzimos uma visão de inimigo da sociedade a ser alvo de castigos como estratégia de defesa social. As noções de risco e de perigo foram criadas na biopolítica para assegurar a função de morte em democracias. Se fazer viver é uma preocupação da entrada da vida na história, para tanto se pode deixar morrer e matar em nome da vida um paradoxo da biopolítica, de acordo com Foucault (1988, 1999b, 2008a). A morte seletiva é sustentada por aparatos de garantia de direitos humanos que, em tese, são justificados pela proteção à vida e em defesa da sociedade.

Uma sociedade de direitos se materializa num conjunto de dispositivos da indústria do medo, da segurança, do encarceramento e da criminalização dos pequenos desvios sociais. Entram em cena projetos de lei e ordem que permitem segregar, matar, intimidar e deixar morrer milhares de pessoas como tática de poder, numa sociedade que fundamenta o controle social na garantia da segurança diante de riscos que se ampliam na medida mesmo em que são operadores vazios, efeitos de táticas biopolíticas e disciplinares. Afirma Souza (2006):

Os riscos na verdade não existem, são
fenômenos criados pelas companhias de
seguro. Os riscos são a objetivação de
determinados acontecimentos: morte,
acidente, ferimento, perda, acaso, sua
regularidade, no tempo e no espaço. ...
As companhias de seguro e as políticas
previdenciárias passam a dar o
referencial para as perdas do sistema 
capitalista e financeiro e, nesse sentido, servem de modelo para as práticas de observação e as práticas judiciais. Os sistemas de observação abrem um campo de visibilidade no qual o que conta são as probabilidades, os cenários em que determinadas configurações e acontecimentos podem penetrar na ordem do cálculo racional. O risco é a colonização do futuro; ele labora as minúcias, os detalhes das configurações numéricas do passado e do presente. $\mathrm{O}$ delito, as violências, as depredações, as greves, as rebeliões, assim como o incêndio, o furacão, a avalancha e o desmoronamento entram na ordem do seguro. O crime que se tornara desvio agora é risco, não é mais construção única do jurídico nem das disciplinas (Souza, 2006, p. 250-251).

Assim, os riscos e os perigos, enquanto virtualidades, passam a requerer que sejam operados por um acúmulo de documentos e registros em nome do governo da vida. Prolifera a elaboração de bancos de dados e de estatísticas e cálculos demográficos de uma geografia do crime e do medo, no mercado da segurança e da seguridade - fomentadores da periculosidade que thes serve de justificação. Esclarece Foucault:

Se eu estudei práticas como as do sequestro dos loucos, ou da medicina clínica, ou da organização da das ciências empíricas, ou da punição legal, foi para estudar um jogo entre um código que regula maneiras de fazer (que prescreve como selecionar as pessoas, como educar os indivíduos etc.) e uma produção de discursos verdadeiros que servem de fundamento, de justificação, de razões de ser e princípio de transformações a essas mesmas maneiras de fazer. Para dizer as coisas claramente: meu problema é saber como os homens se governam (eles próprios e os outros) através da produção da verdade (Foucault, 2006b, p. 342-343).

Prevenir crimes e gerir riscos/perigos colados a determinados grupos sociais destacados como potenciais dissidentes, de maneira racista, pela história de seus desvios das normas nos arquivos da administração social constituem uma prática comum na biopolítica. Para defender a sociedade e a vida de alguns, sacrificam-se os que são forjados como inimigos sociais no regime de escrita e de guarda das fontes documentais:

A noção de periculosidade significa que o indivíduo deve ser considerado pela sociedade ao nível de suas virtualidades e não ao nível de seus atos; não ao nível das infrações efetivas a uma lei efetiva, mas das virtualidades de comportamento que elas representam (Foucault, 1996, p. 85).

A burla da regra passa a ser considerada culpa do indivíduo, para que o Estado se exima e não tenha que gastar com o sistema de saúde de ampla cobertura, por exemplo. $O$ adoecimento vai sendo registrado passo a passo, em prontuários, guias e encaminhamentos, de maneira que também a indústria securitária privada se exima, quando conveniente. Deixar de seguir regras de saúde, no presente, poderá ser imputado como culpa por um adoecimento futuro, sem cobertura de seguro saúde por esse desvio se tornar um registro em algum arquivo da administração.

A busca por segurança e a gestão da insegurança são encomendas que, acionadas pelo racismo de Estado e de sociedade, na biopolítica fazem funcionar sectarismos e fundamentalismos que sustentam clamores por uma sociedade cada vez mais penal e punitiva, como projeto de defesa social. Para tanto, os espaços que operam o dispositivo da confissão como elemento de produção do indivíduo classificado como perigoso socialmente passam a ser alvo de investimento para a gestão do risco e a prevenção de crimes e doenças; mas se for preciso internar e aprisionar como última instância, a sociedade atual e o Estado não pouparão esforços para castigar em nome da vida, invalidando a de outros.

A invenção das figuras do anormal e deste como indivíduo perigoso está interligada com a perseguição aos dissidentes políticos e aos que subvertem a sociedade produtivista e legalista. Por isso, entre as estratégias de regulação das condutas de segurança se encontram as que modulam estatísticas descritivas e inferenciais, marcadamente produtoras de perfis de anormalidade e de controle de risco/perigo racista.

Diante da ampliação das demandas de saúde, proteção social e segurança, o Estado e a sociedade neoliberais vão financiando 
menos as políticas públicas e punindo cada vez mais a quebra de deveres e a desobediência civil. Para cumprir esse mandato, utilizam os inquéritos e os exames como dispositivos auxiliares da fixação dos desvios nos relatórios das delegacias, dos hospitais, da assistência social e do Poder Judiciário. Relatos de um livro de advertência escolar de hoje, uma patologia registrada com um determinado número no Código Internacional de Doenças (CID) e outros tantos registros cada vez mais integrados por sistemas eletrônicos de informação poderão ser transformados em vestígios de julgamentos futuros, como se a vida funcionasse em causa e efeito linearmente.

Um arquivo é fabricado com a preocupação em registrar dados e formular supostas evidências e cálculos probabilísticos para gerenciar vidas na demanda de lei e ordem atual. Torna-se necessário enfatizar de novo que a ancoragem desse processo se dá pela criação de bases de dados em registros detalhados de cada ato em cálculos permanentes, gerando arquivos e saberes para legitimar poderes e práticas jurídicas securitárias articuladoras de lei e ordem, em nome da preservação da vida e da defesa da sociedade contra os que ela venha a declarar como inimigos, o que poderá acontecer com qualquer indivíduo que cometer um crime, acumular desvios das normas sociais ou, meramente, vier a adoecer e demandar por tratamentos que provoquem fissuras na normalização securitária.

Por isso podemos afirmar que as punições mesclam biopolítica com as disciplinas, na busca por segurança, em variados espaços e instituições, em deslizamentos de uma para outra, e também por combinações entre elas, sempre mobilizando arquivos e documentos de uma escrita produtora de tipologias punitivas e medicalizantes. Por exemplo, espaços de punição visam saúde e espaços de cuidado familiar se tornam militares; tribunais entram nas escolas e a educação entra nas prisões; hospitais se tornam fábricas geridas por empresas e quartéis se tornam famílias. Explica Foucault:

A observação prolonga naturalmente uma justiça invadida pelos métodos disciplinares e pelos processos de exame. ... Devemos ainda nos admirar que a prisão se pareça com as fábricas, com as escolas, com as escolas, com os quartéis, com os hospitais, e todos se pareçam com as prisões? (Foucault, 1999a, p. 187).

Algumas práticas psicológicas atuais assumem caráter jurisdicional, numa clara migração de operadores do Poder Judiciário que se traduz numa lógica de encaminhamentos e proliferação documental na forma de prontuários, fichas e outros registros que visam acompanhar aqueles que estão sob a guarda e/ou proteção do Estado. É o que nos mostram Nascimento e Scheinvar (2007) ao estudarem prontuários de atendimento e acompanhamento produzidos e arquivados em conselhos tutelares do Rio de Janeiro. As autoras argumentam que estes equipamentos sociais, mesmo tendo sido propostos como arranjos institucionais pautados pela reivindicação e pela denúncia de violações dos direitos humanos, terminam por atualizar a força da lei jurídica, a hierarquização das decisões características dos tribunais e toda a sua carga de produção de desfiliações sociais, sem operar uma escuta que se oponha à lógica punitiva ou filantrópica:

No Conselho Tutelar os modelos que
prevalecem quando da execução da lei
têm sido os adotados pelo judiciário. Em
geral, não se percebe que práticas
diferentes das jurídicas, como as de
reivindicação política, também se
pautam em leis, sem emitir sentenças,
sem encaminhar medidas particulares,
mas intervindo na ordem pública
(Nascimento \& Scheinvar, 2007, p. 156).

Quem é classificado como em risco ou como perigo e para quem e por que o é? Como se tornar perigoso na escrita dos equipamentos de seguridade e justiça e na avaliação dos especialistas? Os produtores da escrita biopolítica organizam esses arquivos para fazer o quê e encaminhar o quê? Que tipo de sociedade sustenta uma economia punitiva em termos biopolíticos?

\section{ESCREVER A HISTÓRIA POLÍTICA DA VERDADE PARA RESISTIR}

Como efetuar resistências e dissidência política na maneira de escrever, guardar, analisar, encaminhar, decidir, cuidar e proteger? Como fazer contrapoderes na narrativa 
histórica? De que maneira silenciar no documento e subverter nos encaminhamentos e decisões que envolvem poder, norma, verdade, lei, direito, penas e prescrições?

A maneira de realizar as pesquisas históricas de Foucault (2008a) traz contribuições relevantes para criarmos campos de possíveis, pois ele destaca que em todos os seus estudos quis forjar deslocamentos e rupturas dos processos de jurisdicionalização, judicialização e medicalização da vida. Para isso ele estudou arquivos de instituições segregativas onde haviam sido internados grupos alvo dos processos de desfiliação social. Dar visibilidade ao que era feito com esses corpos e aos saberes que sustentavam esses poderes era uma busca incansável das preocupações políticas de Michel Foucault. Seu objetivo era produzir ferramentas de luta contra os intoleráveis do presente com as ferramentas históricas, com os arquivos e fontes referentes aos espaços de cárcere e nas masmorras, nos asilos, nos espaços de isolamento e castigo. Dessa maneira, os documentos puderam ser usados para efetuar contrapoderes e resistir aos processos de tutela, normalização e moralização confessional.

A coragem da verdade como crítica abre brechas de pensamento histórico e opera rupturas relevantes em uma sociedade punitiva e de normalização. São colocadas em xeque as articulações entre leis e normas resultantes de um dispositivo de soberania jurídica acrescido de técnicas disciplinares, de estratégias biopolíticas e securitárias que se assomam sob o clamor pela lei e ordem na esfera da judicialização e da jurisdicionalização da vida.

No bojo da prática de resistência, incluída aí a própria escrita, as existências são deslocadas e as capturas dos movimentos acontecem dinamicamente, atualizando-se e demandando a invenção cotidiana de contracondutas e de problematizações por perguntas que nos ajudem a escrever outras histórias efetivas que sejam críticas e úteis à vida, na medida em que permitam criar campos de possíveis em meio às cristalizações jurídicas e normalizações instituídas.

Usar a história, os documentos e os arquivos no trabalho analítico com a coragem da verdade - em sua efetuação ética, estética e política - implica em habitar os entremeios e ocupar ou até mesmo criar espaços para ocupações inventivas de um direito não normalizado e muito menos normalizador. No mesmo movimento, recusar a política criminal que opera decisões de acirramento penal fazse importante para os que acreditam em uma efetuação ética e não vingativa da Justiça. Tal recusa se estende aos reformismos de Estado sustentados por alianças táticas entre os dispositivos "psi" e jurídicos que visam ao abrandamento dos intoleráveis efetuado, dentre outros procedimentos, pela mitigação do sofrimento e a linearização das vidas como histórias coerentes e encadeadas em prol de uma pretensa cura, reinserção ou mesmo o confinamento alçado ao inevitável pelo recurso ao diagnóstico de periculosidade.

\section{REFERÊNCIAS}

Albuquerque Jr, D. M. (2009). A dimensão retórica da historiografia. In C. B. Pinsky \& T. R. de Luca (Orgs.). O historiador e suas fontes (pp. 223-249). São Paulo: Contexto.

Castro, C. (2008). Pesquisando em arquivos. Rio de Janeiro: Zahar.

Farge, A. (2011). Lugares para a história. Rio de Janeiro: Autêntica.

Foucault, M. (1979). Microfísica do Poder. Rio de Janeiro: Graal.

Foucault, M. (1988). História da Sexualidade I: a vontade de saber. Rio de Janeiro: Graal.

Foucault, M. (1996). Conferência V. In M. Foucault. A verdade e as formas jurídicas (pp. 103-126). Rio de janeiro: Graal.

Foucault, M. (1999a) Vigiar e Punir: a história da violência nas prisões. 19a ed. Petrópolis, RJ: Vozes.

Foucault, M. (1999b). Em defesa da sociedade. São Paulo: Martins Fontes

Foucault, M. (2001). Os anormais. São Paulo: Martins Fontes.

Foucault, M. (2006a). A vida dos homens infames. In M. B. Motta (Org.). Estratégia, poder-sabe (Coleção Ditos \& Escritos, Vol. 4, pp. 203-222). 2a ed. Rio de Janeiro: Forense Universitária.

Foucault, M. (2006b). Poder e saber. In M. B. Motta (Org.). Estratégia, poder-saber (Coleção Ditos \& Escritos, Vol. 4, pp. 223-240). 2a ed. Rio de Janeiro: Forense Universitária.

Foucault, M. (2008a). Nascimento da Biopolítica. São Paulo: Martins Fontes.

Foucault, M. (2008b) Segurança, território e população. São Paulo: Martins Fontes.

Nascimento, M. L. \& Scheinvar, E. (2007). De como as práticas do conselho tutelar vêm se tornando jurisdicionais. Aletheia, 25, 152-162. 
Prado Filho, K (2012). Uma breve genealogia das práticas jurídicas no ocidente. Psicologia \& Sociedade, 24(n.spe.), 104-111.

Souza, L. A. (2006). Paradoxos da modernidade vigiada: Michel Foucault e as reflexões sobre a sociedade de controle. In L. Scavone, M. C. Alvarez \& R. Miskolci (Orgs.). O legado de Foucault (pp. 241-259). São Paulo: UNESP/FAPESP.

Flávia Cristina Silveira Lemos: mestre em Psicologia e Sociedade pela UNESP-Assis, doutora em História pela UNESP-Assis, professora adjunta III em Psicologia e docente no Programa de Pós-graduação em Psicologia na Universidade Federal do Pará, bolsista de produtividade em pesquisa CNPQ-PQ2.

Dolores Cristina Gomes Galindo: mestre em Psicologia Social pela PUC-SP, doutora em Psicologia Social pela PUCSP, professora adjunta do Departamento de Psicologia e do Programa de Pós-graduação em Estudos de Cultura Contemporânea na Universidade Federal de Mato Grosso.

Jorge Moraes da Costa: psicólogo, mestrando em Psicologia na Universidade Federal do Pará, professor do Departamento de Psicologia na mesma universidade. 